\title{
Experiencias educativas entre los mayas de Yucatán: retos y debilidades
}

\author{
Salvador Sigüenza Orozco
}

Jesús Lizama Quijano (coord.), 2008

Escuela y proceso cultural. Ensayos sobre el sistema de educación formal dirigido a los mayas

CIEsas, México, 260 pp.

E scuela y proceso cultural contiene, en su mayoría, textos de antropólogos; pero también presenta una mirada filosófica, educativa e histórica de un tema que se ha discutido desde el siglo XIX, o aún antes: lo que durante mucho tiempo se llamó el problema indígena. Los siete ensayos incluidos en el libro se refieren al sistema de educación formal que recibe la niñez maya en Yucatán.

Un elemento importante para comprender el modelo de educa- ción que actualmente se dirige a los indígenas mexicanos es el conocimiento de sus antecedentes históricos, tema abordado en los textos de Jesús Lizama, Gabriela Solís y, sobre todo, en el de Martha Patricia Mendoza, quien en "Historia de la educación rural en Yucatán (19151940)" se refiere al proceso de construcción de la identidad nacional a través de mecanismos escolares, en el que la castellanización y la alfabetización se consideraron

Educational Experiences Among Yucatan's Mayans: Challenges and Weaknesses

Salvador Sigüenza Orozco: Doctorado en ciencias sociales, Centro de Investigaciones y Estudios Superiores en Antropología Social-Pacífico Sur, México salvadorsgz@yahoo.com

Desacatos, núm. 33, mayo-agosto 2010, pp. 183-186

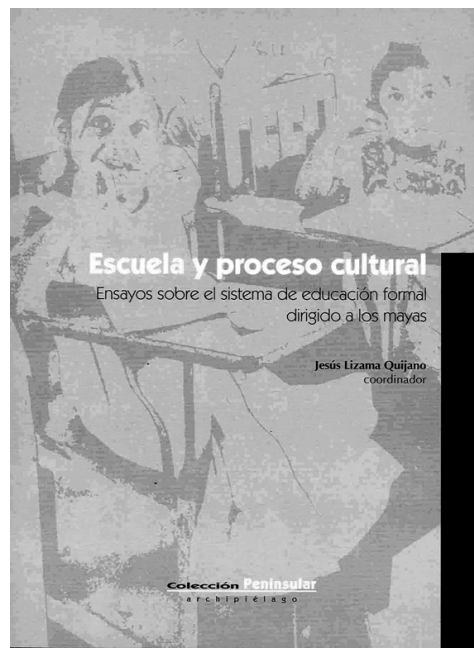

fundamentales para homogeneizar a la nación.

Recuperando algunos de los criterios de la gestión educativa de los gobernadores Salvador Alvarado y Felipe Carrillo Puerto, la autora señala ciertos elementos y características de la incipiente escuela mexicana: la necesidad de improvisar maestros (aunque algunos se contrataron fuera de Yucatán o eran jóvenes yucatecos enviados a la ciudad de México para estudiar), la racionalidad que debería tener la 
enseñanza, el ejercicio de la docencia sólo por personas liberales, incluso las sanciones a los padres que no enviaran a los niños a la escuela. Junto con las campañas sociales impulsadas desde las aulas, se manifestó la complicidad de maestros con hacendados, quienes nombraban a los primeros a cambio de ciertas omisiones en el cumplimiento de sus responsabilidades, lo cual motivaría el establecimiento de los Consejos de Maestros en sustitución de los directores de escuela. También de esos años es el proyecto de la Escuela de Agricultura en la Quinta San Pedro Chuminópolis, de efímera vida (1915-1916).

A finales de la década de 1920, comenzaron a llegar las escuelas de la SEP a Yucatán, y aunque ción y la grandeza de la nación generó que se crearan cooperativas y sindicatos, labor en la que los maestros participaron activamente, así como en la solicitud de dotación o restitución de tierras.

Los otros ensayos del libro contienen información parcial de investigaciones que incluyeron trabajo de campo con diferentes grupos de la población, fundamentalmente maestros y familias, ubicados en contextos urbanos y rurales. Asimismo, son resultado de la observación directa, del muestreo y de la aplicación de entrevistas. Por ello, presentan cuadros e indicadores que permiten una mejor comprensión de los temas abordados y favorecen la profundización en el análisis.

Para seguir un orden cronológico, empezaré por el trabajo de María Dolores Cervera Pacheco: "La construcción cultural de los niños mayas en Yucatán". Partiendo del estudio de "criaturas" de cuatro a 36 meses, la autora se refiere a diferentes formas de socialización y a la construcción de la diferencia cultural, específicamente en la población de Popolá, Kiní, Yotholin, Pustunich, Xaya y Pencuyut, de la que señala particularidades económicas y productivas. Con base en literatura de prácticas de crianza y desarrollo de niños, Cervera subraya la importancia de las enseñanzas maternas para que los niños entiendan y "terminen de recordar su viento” (responsabilidad). Es decir, sean abusados al insertarse adecuadamente en la sociedad a la que pertenecen. La construcción cultural que las ma- dres enseñan en esta etapa se fundamenta en el respeto: aprender a saludar es parte esencial de las formas de relación del niño. Sin embargo, este temprano proceso de socialización suscita las quejas de algunos maestros de primaria, para quienes el rezago educativo se presenta porque los padres mandan a los hijos a trabajar la milpa. Este rechazo nos conduce al texto de Jesús Lizama: "Un panorama del sistema de educación intercultural bilingüe en Yucatán", que entre otros temas aborda precisamente las continuidades y rupturas entre los procesos de socialización primaria (el de la casa) y secundaria (el de la escuela formal). Con base en algunos datos, el autor señala la situación actual de un modelo educativo surgido en la Revolución, con una orientación nacional, al que paulatinamente se le han "arrancado" cesiones hacia las diferencias regionales. En la actualidad, los mayas son entre 30 y $60 \%$ de la población de Yucatán (según lengua y autoadscripción), 8\% son monolingües y el promedio de escolaridad es de 4.1 años. Los espacios de reproducción de la lengua maya — y de la cultura— se reducen al ámbito comunitario y familiar. Esta población recibe —o debería recibir- una educación bilingüe, al menos en los niveles de enseñanza inicial, preescolar y primaria. Sin embargo, la educación en general - y en particular la dirigida a los indígenas - presenta muchos problemas: primarias con un docente, improvisación o ausentismo de profesores, incumplimiento del horario 
escolar, inoperancia de programas compensatorios, escuelas en condiciones materiales deficientes o lamentables. Mientras estas condiciones no sean debidamente analizadas y comprendidas, hablar de educar en la diversidad o de educación bilingüe, bicultural o intercultural no dejará de ser más que un discurso. Entre otros elementos de reproducción, la educación ha generado una sociedad jerárquica. ¿ $\mathrm{No}$ acaso el sistema educativo dirigido a los indios se llama indígena y el "otro" recibe el calificativo de formal? Así, el lenguaje es uno de los primeros elementos que transmite y genera desigualdad.

Esto nos lleva a preguntar: ¿cuál es el papel del maestro? Más aún, ¿quiénes son y qué problemas tienen estos docentes? El trabajo de Jesús Lizama y Gabriela Solís titulado "Los maestros indígenas frente a su ejercicio docente" nos permite ciertas aproximaciones a este universo. A partir de una serie de entrevistas realizadas a cincuenta maestros (la mayoría entre 40 y 55 años) y a igual número de padres de familia, durante el ciclo escolar 2005-2006, Lizama y Solís detectaron los principales problemas en el ejercicio docente así como la motivación para abrazar esta profesión. Las razones para ser maestro bilingüe son: 1) el origen propio, similar al de los alumnos; 2) la intención de mejorar las condiciones de vida de los alumnos; y 3 ) es una opción laboral. Entre los principales problemas que enfrenta la educación se pueden mencionar: los pro- blemas en la lecto-escritura, los índices de reprobación, la deserción, el desplazamiento de la lengua maya, la renuencia de los alumnos a aprenderla. Además, hay problemas de comunicación con padres hablantes de lengua maya, muchos docentes son de edad avanzada, se carece de materiales didácticos, faltan maestros especializados (educación física, artística, especial), la infraestructura es deficiente y las escuelas son de grupos multigrado. Para enfrentar parte de estos problemas, en "Que todos los niños hablen maya”, Teresa Pool señala que la formación de docentes debe profesionalizarse, exigiendo ciertos requisitos: ser licenciados en educación, hablantes de lengua maya, tener el español como segunda lengua, así como los conocimientos pedagógicos o experiencia frente a grupo. Asimismo, será necesario recibir cursos de capacitación, en los que se incluyan conocimientos sobre elaboración de materiales, estrategias de enseñanza y evaluación. Para revertir o intentar subsanar la insuficiente formación de los docentes, se sugiere un impulso más decidido a la labor de instancias como la UPN, que surgió localmente a finales de la década de 1980.

Los tres textos que completan el libro tienen que ver con la vida cotidiana y con el uso de la lengua maya. En "Vida cotidiana, cultura y socialización entre los niños y jóvenes de un albergue escolar indígena", Virginia Noemí Prieto estudia el Albergue Indígena Santiago Pacheco Cruz, al que asisten niños de en- tre cinco y 14 años; la institución se ubica en Tiholop (Yaxcabá) y la autora la describe como un espacio social intermedio entre el hogar y la escuela, que permite regularizar la asistencia, mejorar la alimentación, así como estimular la permanencia y participación infantil en la escuela. Al ser una institución subsidiada, no sólo recibe apoyos oficiales (SEP, Conafe, Liconsa, Diconsa, CDI, IMSS Oportunidades), sino que los padres de familia están obligados a apoyar las actividades del internado, particularmente las productivas. Desde una mirada antropológica, interesada en los niños, la autora señala no sólo la importancia del albergue como elemento de socialización y de reproducción cultural en el que se tiene acceso a un nuevo espacio, complejo y organizado, también refiere elementos que influyen en la percepción social de un albergue, poniendo énfasis en la baja escolaridad de las madres de familia.

Por otra parte, Juan Carlos Mijangos y Fabiola Romero hacen algunas propuestas, tal vez un poco utópicas, para mejorar la educación indígena: 1) que el personal docente estudie la lectura y escritura maya para su enseñanza, porque no se puede enseñar lo que no se conoce; 2) que el español se imparta como segunda enseñanza; 3 ) extender la educación bilingüe a la secundaria y la preparatoria. En este último caso, me atrevo a sugerir que primero debe consolidarse el sistema en primaria, pues los retos y debilidades apuntados a lo largo del libro per- 
miten considerar que es necesario afianzarlo. Las propuestas de Mijangos y Romero, contenidas en "Usos del español y el maya en la educación primaria bilingüe en Yucatán. Un aspecto de la desigualdad", se basan en el estudio realizado en nueve primarias indígenas mediante descripciones etnográficas de las prácticas sociales, el mundo cotidiano y los procesos de socialización. Los autores enfatizan el uso del lenguaje como artefacto cultural que, además de otorgar significado a las cosas, se convierte en elemento de mediación cultural. Y al hablar de lenguaje hablamos de la oralidad maya, de experiencias de escritura indígena y de relaciones sociales, inequitativas en la medida en que el bilingüismo no deja de ser sólo enunciativo.

Existe un libro que se llama Porque hablar dos idiomas... es como saber más. Tal vez a eso se refiera Teresa de Jesús Pool Ix al exponer sus reflexiones a través de "Que todos los niños hablen maya. El programa Ko'one' ex Kanik Maaya a 15 años de su implantación". Considerando que la escuela formal transmite prejuicios y estereotipos, $y$ sobre todo que era importante recuperar la lengua y la cultura mayas, este programa se inició en 1990. Dirigido a niños no hablantes de maya, empezó en los suburbios de la ciudad de Mérida, encaminado a implantar el uso de cuatro habilida- des comunicativas: 1) la comprensión auditiva; 2) la producción oral; 3) la comprensión de la lectura; y 4) la producción escrita. A pesar de la renuencia de padres y de profesores, y convencido de la necesidad de revalorar la lengua maya con el apoyo de los maestros, el programa llegó a trabajar en 66 primarias y 25 secundarias, con el objetivo de favorecer el pluralismo cultural y la equidad social, así como garantizar la vigencia de la lengua maya. La autora señala que el principal logro fue mejorar la conciencia del valor de la lengua maya. Sería interesante conocer una evaluación más amplia de dicho programa.

Hasta ahora, no he hecho más que referirme a algunos aspectos presentes en los ensayos: la marginación y pobreza, la desigualdad, el analfabetismo, la deserción, la reprobación y la discriminación; en general, las carencias del subsistema de educación indígena. Indudablemente no son temas nuevos, la cuestión es ¿por qué siguen teniendo vigencia? Porque es importante decirlo, no se han logrado cambios significativos y hay que hacer más. Las actuales necesidades comunicativas tienden a la riqueza y a la diversidad, pero esto no debe ser sólo un discurso, sino un ejercicio cotidiano. Conocer más permite comprender mejor. Éste es un problema actual, en un contexto en el que el concepto intercultural no se comprende cabalmente.

En términos históricos, el desplazamiento de la lengua maya ha transformado los usos y repertorios locales, modificando la relación entre lenguaje y experiencia cultural acumulada. Dicho desplazamiento, por medio de un proceso de sustitución, tiene que ver con el discurso público transmitido fundamentalmente por la escuela, el cual se puede caracterizar por su valor simbólico, su ejercicio, su manipulación y sus consecuencias. Estas características permiten una primera aproximación a los procesos y tensiones que se presentan cuando una lengua — en este caso, escritadesplaza a otra - generalmente oral—, propiciando el surgimiento de la categoría de discurso oculto y de fenómenos de discriminación y proscripción. En tanto las lenguas no tengan una relación, si no de igualdad, por lo menos de equilibrio, las relaciones sociales seguirán reproduciendo y ahondando desigualdades. Por ello, textos como el coordinado por Lizama, construidos a partir de la experiencia diaria y del sentir y saber de los directamente involucrados en las tareas educativas y en la conservación y reproducción de la lengua maya, brindan elementos para reflexionar sobre el tema, sobre todo en una cultura tan pródiga como la maya. 